\title{
Size and separability of the calcaneal and the medial and lateral plantar nerves in the distal tibial nerve
}

\author{
Lotte N. S. Andreasen Struijk - Henrik Birn • \\ Peter S. Teglbjærg · Jens Haase · Johannes J. Struijk
}

Received: 25 November 2008/Accepted: 15 April 2009/Published online: 16 May 2009

(C) Japanese Association of Anatomists 2009

\begin{abstract}
The tibial nerve (TN) has three main terminal branches: the medial and lateral plantar nerves and the calcaneal branch (CB), which innervates the foot sole. The design and implantation of nerve cuff electrodes with separate channels for each of these three terminal branches would provide significant sensory information, which can be used in functional electrical stimulation systems to assist standing or to correct foot drop. Detailed quantitative anatomical data about fascicular size and separability of the terminal branches of $\mathrm{TN}$ are needed for the design and implantation of such cuff electrodes. Therefore, the branching pattern, the fascicular separability and the fascicular size of the TN posterior to the medial malleolarcalcaneal axis were examined in this study, using ten human TN specimens. The TN branching patterns were highly dispersed. For the CBs, multiple branches were identified in five $(50 \%)$ of the specimens. For the TN, the bifurcation point was located within the tarsal tunnel in eight $(80 \%)$ of the cases. The distance proximal to the medial malleolar-calcaneal axis for which the TN could be split ranged form 0 to $41 \mathrm{~mm}$. Quantitative and qualitative data were obtained for the fascicular size and separability
\end{abstract}

L. N. S. Andreasen Struijk ( $($ ) · J. Haase · J. J. Struijk

Center for Sensory-Motor Interaction,

Department of Health Science and Technology,

Aalborg University, Fredrik Bajers Vej 7 D3,

9220 Aalborg, Denmark

e-mail: naja@hst.aau.dk

H. Birn

Institute of Anatomy,

Aarhus University, Aarhus, Denmark

P. S. Teglbjærg

Institute of Pathology, Aalborg Hospital,

Århus University Hospital, Aarhus, Denmark of the TN. Only the CB of the TN proved separable for a sufficient length for nerve cuff electrode implantation. The results suggest the use of a two-channel cuff with one common channel for the lateral and medial plantar nerves, having multiple electrodes for selective recording, and one channel for the CB.

Keywords Tibial bifurcation and fascicular distributions - Calcaneal branch pattern - Fascicular size and separability of the medial and lateral plantar nerves and the calcaneal branches - Cuff electrodes

$\begin{array}{ll}\text { Abbreviations } \\ \text { CB } & \text { Calcaneal branch } \\ \text { FES } & \text { Functional electrical stimulation } \\ \text { LPN } & \text { Lateral plantar nerve } \\ \text { MMCA } & \text { Medial malleolar-calcaneal axis } \\ \text { MPN } & \text { Medial plantar nerve } \\ \text { SNR } & \text { Signal-to-noise ratio } \\ \text { TN } & \text { Tibial nerve } \\ \text { TT } & \text { Tarsal tunnel }\end{array}$

\section{Introduction}

The distal part of the tibial nerve (TN) branches into the calcaneal branch (CB), the medial plantar nerve (MPN) and the lateral plantar nerve (LPN). These branches innervate the calcaneal, the medial plantar and the lateral plantar areas of the foot, respectively (See Fig. 1), and carry sensory information from those areas.

Sensory information from the skin and from muscles and tendons as well can be used as a feedback signal for a functional electrical stimulation (FES) system used to 


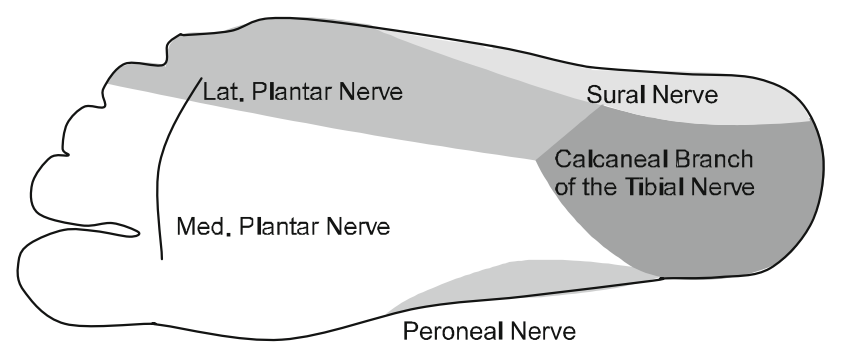

Fig. 1 Schematic drawing representing the areas innervated by the three main sensory nerves of the foot sole. Adapted from Gray (1995)

stimulate paralysed muscles for the restoration of movement in spinal cord-injured individuals (Haugland et al. 1997; Havel et al. 1988; Navarro et al. 2005). One modality to obtain such information is the use of a cuff electrode as a neural interface, enabling the recording of compound nerve signals, which includes the sensory information carried by the nerve (Andreasen and Struijk 2002, 2006; Andreasen et al. 2000; Haugland et al. 1997; Havel et al. 1988; Hoffer 1990; Stein et al. 1975).

The distal TN with its branches is of special interest for FES applications such as the correction of foot drop (Haugland and Sinkjær 1995) and FES for standing and walking of spinal cord-injured people (Andreasen and Struijk 2003a). In the case of a foot drop FES system, the $\mathrm{CB}$ will convey information about the heel strike and the heel lift, whereas the MPN and the LPN carry information about the floor contact of their respective innervation areas, which may be used to detect inversion or eversion of the foot during walking. The heel-contact signal is essential for timing of the peroneal nerve stimulation in a foot drop system, whereas inversion or eversion may call for a change of the stimulation parameters. In the case of FES for standing and walking, in addition to the information mentioned above, the nerve signals from the three innervation areas give information about the centre of pressure (Andreasen and Struijk 2003a), which is needed for the control of standing.

Ideally, a nerve cuff electrode should be placed on each of the three terminal branches of the TN to obtain maximally selective signals from the three main innervation areas (see Fig. 1) and to obtain a maximal signal-to-noise ratio (SNR). Alternatively, a multichannel cuff with three separate channels, one for each of the three branches of the TN, could be used. The SNR is optimised by the choice of a cuff electrode with the lowest possible diameter (Struijk 1997). However, a tightly fitting cuff may induce nerve damage (Hoffer 1990). These requirements for the cuff design and implantation pose two questions: (1) can the branches of the TN be safely separated from each other to allow for a multichannel-cuff implant, and (2) what are the dimensions of the three nerves?
Qualitative descriptions of the TN and its branches are readily available in the literature, but detailed quantitative data are not given anywhere. At the level of the ankle, the TN bifurcates into the MPN and LPN (see Fig. 2). This bifurcation point varies only a little among specimens, whereas a great dispersion exists in the bifurcation level of the CB. Most studies indicate that the tibial bifurcation is located in the tarsal tunnel in the great majority of cases (Table 1). Davis and Schon (1995) found that the TN divides within the tarsal tunnel, within $2 \mathrm{~cm}$ of the medialmalleolar-calcaneal axis (MMCA, see Fig. 2) in 16 out of 18 feet. In the remaining two feet the bifurcation took place 5 and $9 \mathrm{~cm}$ proximal to the MMCA. However, Bareither et al. (1990) identified the bifurcation more proximally in up to $31 \%$ of the feet studied. A single case in which the TN completely failed to divide into terminal branches has been reported as well (Sammarco and Conti 1994), but this must be considered to be extremely seldom.

In order to place a cuff electrode on the $\mathrm{TN}$, in which the fascicles of the CB, LPN and MPN run inside separate channels, the branches have to be separated proximal to the tarsal tunnel. In this work we examine the dimensions and the separability of the CB, LPN and MPN, and the location of the bifurcation point of the TN and the branching point of the CB. The examination is based on cross-sections of the studied nerves allowing for the study of the fascicular branching pattern at the perineural level, the importance of which was recently emphasised by Kudoh and Sakai (2007).

\section{Materials and methods}

\section{Anatomy}

\section{The medial plantar nerve}

The MPN is the largest and most anterior of the terminal branches of the TN. It has muscular, cutaneous, articular and vascular branches and supplies the medial part of the foot sole, anterior to the heel (see Fig. 1). As soon as the nerve enters the sole of the foot, its cutaneous branches arise and course downward in the interval between the abductor of the big toe and the flexor digitorum brevis to supply the inner aspect of the foot sole. The cutaneous branches anastomose with terminal branches of the medial calcaneal nerve (Sarrafian 1983).

\section{The lateral plantar nerve}

The LPN has muscular, cutaneous, articular and vascular branches and supplies the lateral part of the foot sole, anterior to the heel (see Fig. 1). After the bifurcation of the 
Fig. 2 The tibial nerve bifurcates into its terminal branches below the flexor retinaculum, at the medial malleolus-calcaneal axis. The right side of the figure shows cross-sections of nerve N9 in this study. The cross-section at the bottom shows clearly separable fascicles of the LPN, MPN and the CB. In the crosssection shown in the middle, the line indicates where the fascicles can be separated. The top figure of the cross-sections shows the same nerve $1 \mathrm{~mm}$ more proximally. The perineurium of the MPN and LPN can no longer clearly be distinguished, and the fascicles have merged

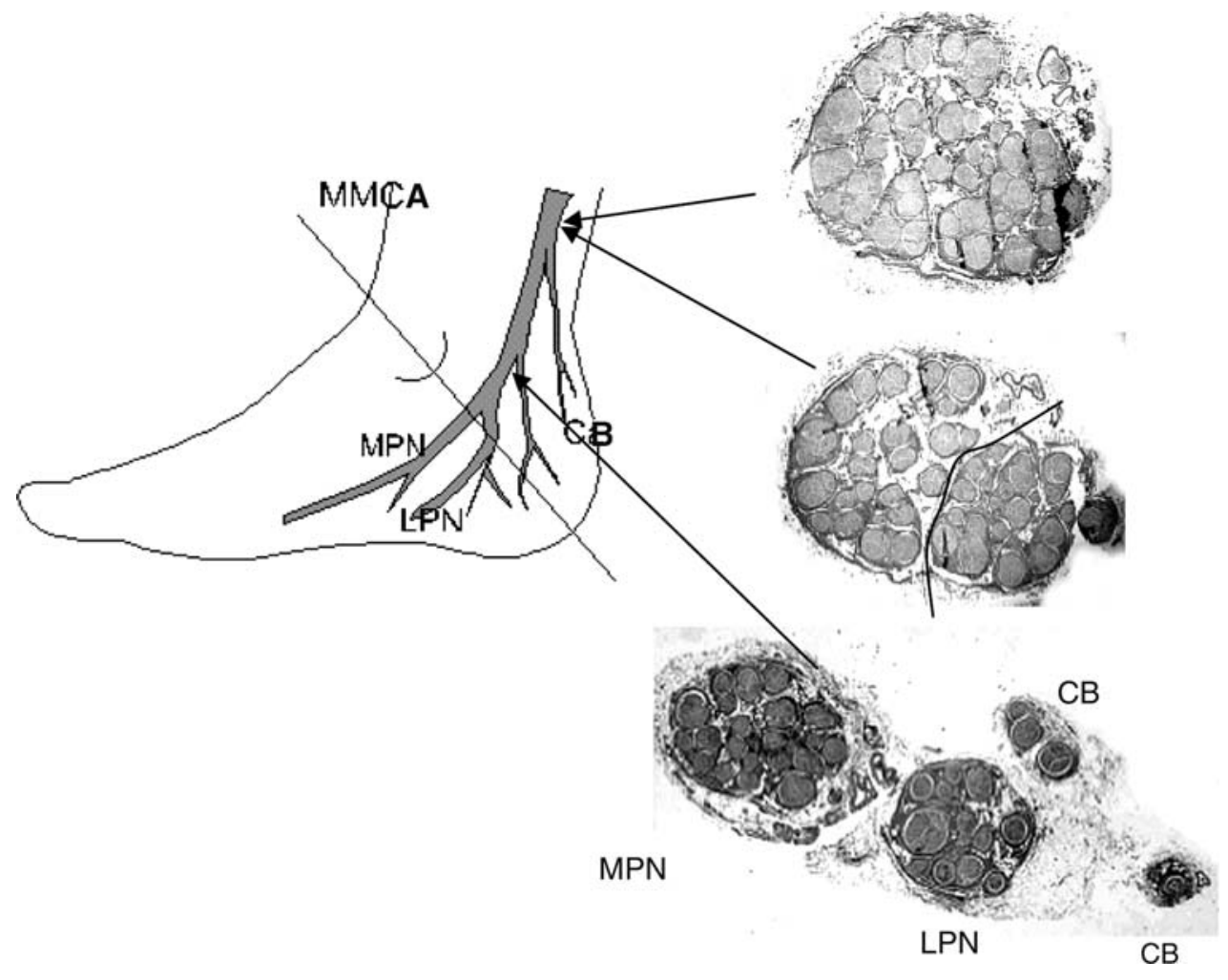

Table 1 Bifurcation patterns of the tibial nerve modified from Davis and Schon (1995)

\begin{tabular}{|c|c|c|c|c|}
\hline Author (year) & $\begin{array}{l}\text { Specimens } \\
(N)\end{array}$ & $\begin{array}{l}\text { Bifurcation in tarsal } \\
\text { tunnel }^{\mathrm{a}}(\%)\end{array}$ & $\begin{array}{l}\text { Bifurcation proximal } \\
\text { to the tarsal tunnel }{ }^{\mathrm{a}}(\%)\end{array}$ & $\begin{array}{l}\text { Bifurcation distal to the } \\
\text { tarsal tunnel }^{\mathrm{a}}(\%)\end{array}$ \\
\hline Horwich (1938) & 100 & 96 & 4 & 0 \\
\hline Dellon and Mackinnon (1984) & 31 & 94 & 6 & 0 \\
\hline Havel et al. (1988) & 68 & 93 & 7 & 0 \\
\hline Nagoaka (1990) & 62 & 85 & 15 & 0 \\
\hline Bareither et al. (1990) & 126 & 69 & 31 & 0 \\
\hline Davis and Schon (1995) & 20 & 90 & 10 & 0 \\
\hline Current study, Andreasen Struijk et al. (2009) & 10 & 80 & 10 & 10 \\
\hline
\end{tabular}

${ }^{\text {a }}$ Data are expressed as $\pm 2 \mathrm{~cm}$ from the MMC axis

TN, the LPN is located more posteriorly than the MPN. Two centimetres within its origin (Davis and Schon 1995), the LPN gives off a rather large muscular branch to the abductor digiti quinti, which courses almost transversely laterally anterior to the calcaneal tuberosities. This branch has often been referred to as a CB (Davis and Schon 1995).

\section{The calcaneal branch}

Newer studies of the CB patterns show a high variability among specimens in both number and origin of the $\mathrm{CB}$ (Davis and Schon 1995; Dellon and MacKinnon 1984; Havel et al. 1988), and some variability also exists between the feet of the same individual. The medial CB often branches from the TN in the distal third of the leg and divides into two branches. The posterior branch covers the skin at the medial part of the Achilles and the posterior part of the heel. The anterior branch is a plantar branch, covering the posterior part of the foot sole. It courses along with the inner border of the foot, and some of its terminal branches anastomose with branches of the neighbouring nerves: the sural nerve, the CBs of the saphenous nerve and cutaneous branches of the LPN and MPN (Sarrafian 1983). Besides the cutaneous branches, the proximal CB, instead of the terminal portion of the $\mathrm{TN}$, provided small articular branches and vascular branches to the posterior tibial artery in the cases studied by Davis and Schon (1995).

The diameter of the $\mathrm{CB}$ is rather small as compared to the ones of the MPN and LPN. 


\section{Material}

The study was performed on ten TNs (three from left legs and seven from right legs) dissected from ten different human cadavers donated to the Anatomical Institute at the University of Aarhus, Denmark. None of the dissected cadavers showed any evidence of nerve disease or damage. The cadavers were routinely fixed by perfusion with formalin within $24 \mathrm{~h}$ postmortem.

\section{Nerve processing}

The TNs were dissected from a point at least $6 \mathrm{~cm}$ above the MMCA to a point well beyond the branching point into the LPN and MPN. During dissection all branches were marked with coloured threads and carefully described on a drawing of the nerve. The dissected nerve segment was gently removed, mounted on a cork board and further fixed in $2.5 \%$ glutaraldehyde in Sørensen's phosphate buffer, $\mathrm{pH}=7.2-7.4$ (Hospital Pharmacy, Aarhus County Hospital, Aarhus, Denmark) for a time period ranging from a few days to 5 months.

Prior to the embedding in paraffin, the nerves were cut transverse to the nerve axis at the level where the MMCA crossed the centre of the nerve. The length of the TN, the location of its branch points and the diameter of the branches at different locations along the $\mathrm{TN}$ posterior to the MMCA were measured using a microscope and a slide gauge. The nerves were dehydrated overnight and embedded in paraffin using a standard laboratory machine (LEICA tissue processor). To prepare the nerve for microtome slicing, the paraffin-embedded nerve was cut in 3-mm-long pieces and mounted vertically in blocks filled with paraffin to be sliced perpendicularly to the nerve axis. For each $0.5 \mathrm{~mm}$ of the length of the nerve, three 4- $\mu \mathrm{m}$-thick slices were cut using a sliding microtome. The slices were straightened in the water bath, and one of the three slices was stained using Masson's trichrome, after which all the slices were mounted on glass plates.

The glass plates were mounted on a microscope and photographed. Preliminary experiments on a single nerve showed that it was sufficient to examine sections representing every $1 \mathrm{~mm}$ length of the nerve in order to be able to study the fascicular separability of the nerve. The total magnification was 11.5-17.8 times, as determined from photographs of a scale.

\section{Data analysis}

The distance for which the TN could be separated into the LPN, MPN and CB was determined from the photographs. The fascicles were considered to be separable if each of the fascicle groups had clear separate perineuriums (see Fig. 2) and a separate vascular supply (the fascicles were considered to have a separate vascular supply if the vascular supply was located within the fascicle groups or in the epineurium at either of the fascicles. If the main vascular supply was located between the fascicles, it was considered to be common, since the fascicles could not be split without injuring the supply). When this was no longer the case, it was concluded that the fascicles had merged and could no longer be safely separated.

The height and width of the cross-section of the fascicle groups belonging to the MPN, LPN and the CB, as well as the total cross-sectional height and width of the TN, were measured at the MMCA and at the merge points. The measurements were performed on the photographs, and the metric data were calculated using the known magnification. Measurements of fascicle group sizes with and without connective tissue were performed at the widest part of each group of fascicles and in a direction perpendicular to that line (Fig. 3).

\section{Results}

\section{Bifurcation of the tibial nerve}

In eight of the ten nerves, the bifurcation was located in the tarsal tunnel (TT: within $\pm 2 \mathrm{~cm}$ of the MMCA). Four of these $(50 \%)$ divided distal to the MMCA. The remaining two nerves, which did not bifurcate in the TT, bifurcated $27 \mathrm{~mm}$ distal to and $24 \mathrm{~mm}$ proximal to the MMCA, respectively. The very distal bifurcation has not been described in the previous studies, as shown in Table 1. It should be noted that the number of specimens in the current study is relatively small, as compared to the other studies

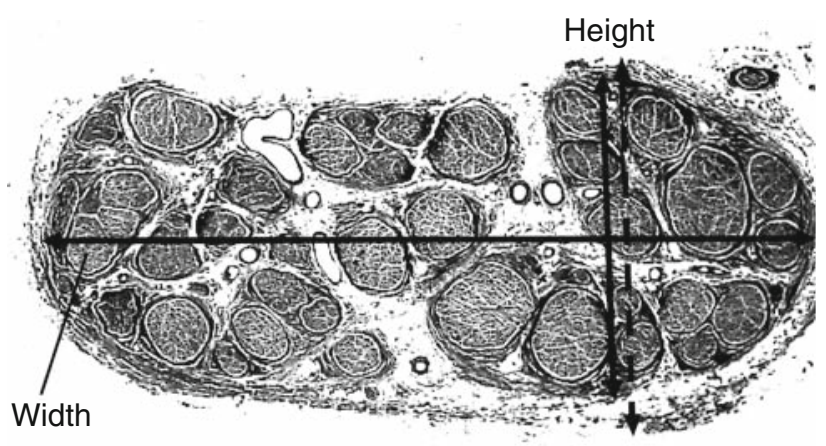

Fig. 3 The measurement of TN cross-sectional diameters. The dotted line shows an example of how the measurements are made with connective tissue. The increase in diameter caused by the connective tissue is included in Table 4 and is given as a number in braces following the measured nerve diameters without connective tissue 
shown in Table 1. This is due to the time-consuming quantitative approach of the current work.

In all ten cases the MPN was located anterior to the LPN.

\section{Calcaneal branch patterns}

In five of the ten specimens analysed, two CBs were identified, in good agreement with the results of a study performed by Davis and Schon (1995) (Table 2). In three of these five cases, one of the two CBs descended separately from the $\mathrm{TN}$, separating from the $\mathrm{TN}$ at a point more than 7-10 cm proximal to the MMCA. In these three cases, the second $\mathrm{CB}$ originated either from the posterior side of the TN in the TT (one case) or from the anterior side of the $\mathrm{TN}$ in the TT (two cases).

In the two cases without separately descending $\mathrm{CBs}$, one $\mathrm{CB}$ originated from the posterior side of the $\mathrm{TN}$ in the TT and one from the anterior side. In one of these cases the anterior CB originated directly from the MPN. This origin is in accordance with the findings of Havel et al. (1988) and Davis and Schon (1995), but was not seen by Horwich (1938) and Dellon and Mackinnon (1984).

In the present study, the CB from the anterior side of the TN usually innervated the anterior part of the skin under the heel, while the posterior branch innervated the more posterior part of the skin.

In total five of the ten specimens had CBs descending separately from locations more than $7-10 \mathrm{~cm}$ proximal to the MMCA; in two of these cases the separately descending $\mathrm{CB}$ was the only $\mathrm{CB}$.

In one case with a single $\mathrm{CB}$, this branch originated from the medial part of the $\mathrm{TN}$, between the locations of the MPN and LPN. This was also the only case where the location of the CB point was proximal to the TT. All other $\mathrm{CB}$ points were located in the TT (except for the cases with separately descending $\mathrm{CBs}$ ).
External measures of the tibial nerve

These external measurements of the TN were made after fixating the nerve in formaldehyde, but before dehydrating and embedding the nerve in paraffin.

The total cross-sectional dimensions of the $\mathrm{TN}$ and of the separate $\mathrm{CBs}$ were measured at different locations along the nerve (Table 3$)$. These five locations $(0,30,45$, 75 and $90 \mathrm{~mm}$ ) are defined in the proximal direction, relative to the MMCA. The external measures include both the fascicles and the connective tissue.

The cross-sectional area of the TN was elliptic, and the height and the width of the ellipse were measured as shown in Fig. 3. While the TN was merely oval in the more proximal end of the specimens, it flattened close to the MMCA. There was a large variability in the cross-sectional size of the TN. At the MMCA, the width varied within 3.3$3.9 \mathrm{~mm}$ and the height within $5.7-8.7 \mathrm{~mm}(n=4)$. At a location $70-75 \mathrm{~mm}$ proximal to the MMCA, the crosssectional width varied within $2.4-3.5 \mathrm{~mm}$ and the height varied within $4.0-8.6 \mathrm{~mm}(n=10)$.

Internal measurements and fascicular separation

\section{Location of the bifurcation and branch points}

The external measurements of the location of the bifurcation and branch points of the LPN, MPN and the CB are shown in Tables 4 and 5, together with the internal measurements of the cross-sectional size of the fascicles of the LPN, MPN and the CBs. In addition, the potential fascicular separation lengths of the MPN, the LPN and the CBs within the TN are shown in Tables 4 and 5 .

At, or distal to, the bifurcation point, the TN gave off a motor branch to the abductor digiti minimum. Usually this branch merged with the LPN and was included in the LPN fascicular group in the measurements, and thus it was included in the MPN group in a few cases only. In the cases

Table 2 Branching patterns of the calcaneal branch modified from Davis and Schon (1995)

\begin{tabular}{|c|c|c|c|c|c|c|c|c|c|}
\hline \multirow[t]{2}{*}{ Author (year) } & \multirow{2}{*}{$\begin{array}{l}\text { Specimens } \\
(N)\end{array}$} & \multicolumn{2}{|c|}{ Branches } & \multicolumn{3}{|c|}{ Origin: location } & \multicolumn{3}{|c|}{ Origin: nerve } \\
\hline & & $\begin{array}{l}\text { One } \\
(\%)\end{array}$ & $\begin{array}{l}\text { Multiple } \\
(\%)\end{array}$ & $\begin{array}{l}\text { TT only } \\
(\%)\end{array}$ & $\begin{array}{l}P \text { only } \\
(\%)\end{array}$ & $\begin{array}{l}\text { Both } \\
(\%)\end{array}$ & $\begin{array}{l}\mathrm{TN} \\
(\%)\end{array}$ & $\begin{array}{l}\text { LPN } \\
(\%)\end{array}$ & $\begin{array}{l}\text { MPN } \\
(\%)\end{array}$ \\
\hline Horwich (1938) & 100 & - & - & 96 & 4 & 0 & 4 & 96 & 0 \\
\hline Dellon and Mackinnon (1984) & 20 & 75 & 25 & 35 & 40 & 25 & 87 & 13 & 0 \\
\hline Rondhuis and Hudson (1986) & 34 & 100 & 0 & - & - & - & 100 & 0 & 0 \\
\hline Havel et al. (1988) & 68 & 79 & 21 & 56 & 37 & 7 & 78 & 29 & 6 \\
\hline Davis and Schon (1995) & 20 & 40 & 60 & 30 & 35 & 35 & 95 & 10 & 15 \\
\hline Current study Andreasen Struijk et al. (2009) & 10 & 50 & 50 & 40 & 30 & 30 & 100 & 0 & 10 \\
\hline
\end{tabular}

$T T$ tarsal tunnel, $P$ proximal, $T N$ tibial nerve, $L P N$ lateral plantar nerve, $M P N$ medial plantar nerve 
Table 3 The external dimensions of the tibial nerve

\begin{tabular}{|c|c|c|c|c|c|}
\hline Nerve & $\begin{array}{l}\text { Size at MMCA } \\
(0 \mathrm{~mm})(\mathrm{mm})\end{array}$ & $\begin{array}{l}\text { Size at } 30 \mathrm{~mm} \\
(\mathrm{~mm})\end{array}$ & $\begin{array}{l}\text { Size at } 45 \mathrm{~mm} \\
(\mathrm{~mm})\end{array}$ & $\begin{array}{l}\text { Size at }(1): 70 \mathrm{~mm} \\
\text { or }(2): 75 \mathrm{~mm}(\mathrm{~mm})\end{array}$ & $\begin{array}{l}\text { Position/size size at } \\
90 \mathrm{~mm} \text { or more }(\mathrm{mm})\end{array}$ \\
\hline \multicolumn{6}{|l|}{ N2 } \\
\hline Tibial & - & w:4.5, h:2.6 & w:4.5, h:2.6 & $2-w: 5.3, h: 2.6$ & \\
\hline Calcaneal & - & w: $1.5, \mathrm{~h}: 1.0$ & w: $1.5, \mathrm{~h}: 1.0$ & 2 -w:1.2, h:1.2 & \\
\hline \multicolumn{6}{|l|}{ N3 } \\
\hline Tibial & - & w:8.5, h:3.1 & w:8.5, h:2.8 & 2-w:8.6, h:2.4 & \\
\hline \multicolumn{6}{|l|}{ N4 } \\
\hline Tibial & - & w:6.2, h:3.1 & w:5.4, h:2.4 & 1 -w:4.3, h:3.4 & \\
\hline \multicolumn{6}{|l|}{ N7 } \\
\hline Tibial & - & w:5.2, h:3.5 & w:5.8, h:3.0 & 1 -w:5.8, h:2.6 & \\
\hline N8 & & & & & Position: $90 \mathrm{~mm}$ \\
\hline Tibial & - & w:5.1, h:3.1 & $\mathrm{w}: 4.4, \mathrm{~h}: 3.0$ & $2-\mathrm{w}: 4.0, \mathrm{~h}: 2.8$ & $\mathrm{w}: 3.8, \mathrm{~h}: 3.0$ \\
\hline Calcaneal & $\mathrm{w}: 2.2, \mathrm{~h}: 1.3$ & Runs on surface of TN & Runs on surface of TN & Runs on surface of TN & Runs on surface of $\mathrm{TN}$ \\
\hline Calcaneal & $\mathrm{w}: 2.2, \mathrm{~h}: 1.2$ & Runs in TN & & & \\
\hline N9 & & & & & Position: $92 \mathrm{~mm}$ \\
\hline Tibial & w:7.2, h:3.7 & w:5.0, h:3.7 & w:4.6, h:3.7 & $2-w: 4.7, h: 3.3$ & $\mathrm{w}: 4.2, \mathrm{~h}: 2.7$ \\
\hline Calcaneal & w: $1.2, \mathrm{~h}: 0.8$ & w:0.9, h:0.7 & w:1.0, h:0.6 & $2-w: 1.0, \mathrm{~h}: 0.6$ & w:0.6, h:0.6 \\
\hline Calcaneal & w: $1.0, \mathrm{~h}: 1.0$ & Runs in TN & & & \\
\hline LPN & $\mathrm{w}: 5.2, \mathrm{~h}: 2.8$ & Runs in TN & & & \\
\hline MPN & w:5.9, h:2.8 & Runs in TN & & & \\
\hline N10 & & & & & Position: $108 \mathrm{~mm}$ \\
\hline Tibial & w:7.2, h:3.7 & w:5.5, h:3.5 & w:5.3, h:3.2 & $2-w: 5.3, h: 2.6$ & $\mathrm{w}: 5.3, \mathrm{~h}: 2.1$ \\
\hline Calcaneal & w:1.4, h:1.0 & w:1.2, h:0.7 & w:1.0, h:0.8 & 2—w:0.9, h:0.7 & Runs in TN \\
\hline N11 & & & & & Position: $97 \mathrm{~mm}$ \\
\hline Tibial & w:5.7, h:3.9 & w:4.4, h:3.6 & w:4.9, h:3.5 & 2-w:4.0, h:3.5 & w:3.6, h:3.2 \\
\hline N12 & & & & & Position: $100 \mathrm{~mm}$ \\
\hline Tibial & w: $8.7, \mathrm{~h}: 3.3$ & w:6.2, h:3.4 & w:5.0, h:3.3 & 2-w:4.4, h:3.1 & w:5.3, h:3.0 \\
\hline N13 & & & & & Position: $100 \mathrm{~mm}$ \\
\hline Tibial & - & w:3.1, h:4.9 & w:5.2, h:3.2 & 2-w:4.9, h:2.9 & w:5.8, h:2.3 \\
\hline Calcaneal & w: $1.8, \mathrm{~h}: 1.3$ & - & - & - & - \\
\hline Calcaneal & w:1.0, h:0.7 & Runs in TN & & & \\
\hline LPN & w: $4.8, \mathrm{~h}: 2.2$ & Runs in TN & & & \\
\hline MPN & w:5.3, h:2.1 & Runs in TN & & & \\
\hline
\end{tabular}

Position is taken in the proximal direction, relative to the MMCA

where the TN bifurcated proximal to the MMCA, the measured size of the $\mathrm{TN}$ is rather large due to the distance between the LPN and MPN. In one nerve (N12), a small branch w:0.4 and h:0.3 mm branching off from the MPN, merged $7 \mathrm{~mm}$ proximal to the MMCA and was not included in the measurements.

\section{Fascicular separability}

There were major differences in the fascicular separability of the TN into the LPN, MPN and CB (Tables 4, 5). The separable length was $0-41 \mathrm{~mm}$, measured from the MMCA in the proximal direction. In average the $\mathrm{TN}$ was separable into the LPN and MPN for a length of $18.7 \mathrm{~mm}(n=10)$.
This number includes the nerves, in which the TN bifurcated proximal to the MMCA, which means that the LPN and MPN run as separate nerves in the distal part of the length used for the calculation of the average value shown above. In two cases (N7 and N12 in Table 4), there was no separability of the TN. In one case (N7 in Table 4) the merge point was found from the photographs to be distal to the bifurcation point measured externally. The reason for this is the shrinkage and loss of nerve tissue due to the processing of the nerve performed before the photographs were taken, as further described in the discussion.

Excluding the five CBs that were descending separately from locations more proximal than $70 \mathrm{~mm}$ from the MMCA, the CBs were running separately or were separable 


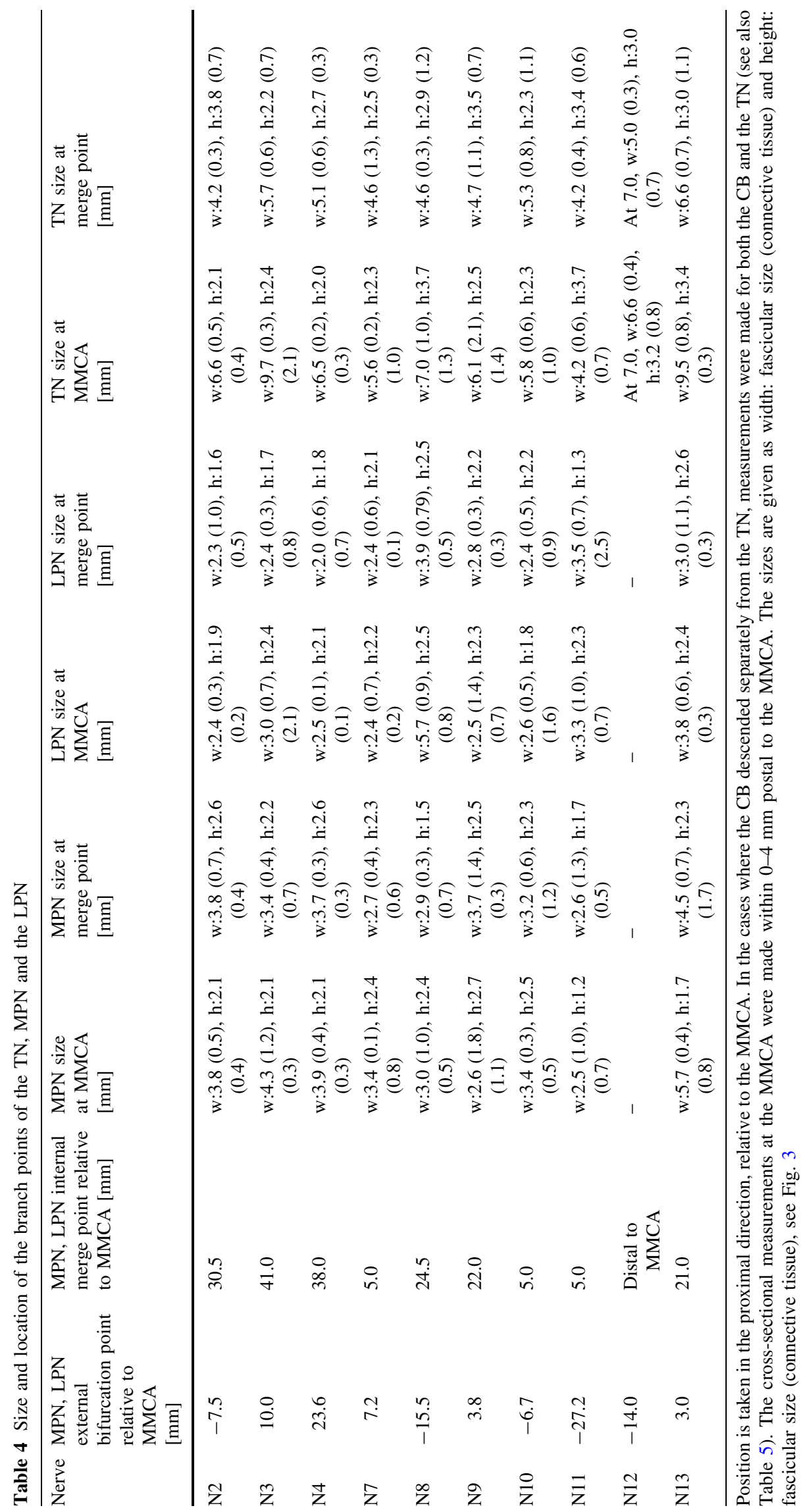


Table 5 Size and location of the branch points of the CB

\begin{tabular}{|c|c|c|c|c|c|}
\hline Nerve & $\begin{array}{l}\text { Origin and external } \\
\text { location of branch point, } \\
\text { relative to MMCA [mm] }\end{array}$ & $\begin{array}{l}\text { Internal location of merge } \\
\text { point relative } \\
\text { to MMCA }[\mathrm{mm}]\end{array}$ & $\begin{array}{l}\text { Cross-sectional size } \\
\text { at the MMCA }[\mathrm{mm}]\end{array}$ & $\begin{array}{l}\text { Cross-sectional size } \\
\text { at the merge point }[\mathrm{mm}]\end{array}$ & $\begin{array}{l}\text { Number } \\
\text { of CBs }\end{array}$ \\
\hline $\mathrm{N} 2$ & Separately descending & Proximal to 77.0 & w:1.1 (0.2), h:0.8 (0.5) & w:0.9 (0.6), h:0.5 (0.7) & 1 \\
\hline N3 & $8.8 \mathrm{TN}$ posterior & Proximal to 68.0 & w:1.6 (2.6), h:1.1 (1.9) & w:1.2 (1.1), h:0.7 (1.9) & 1 \\
\hline N4 & 23.6 TN central & 21.0 & w:1.8 (0.2), h:0.9 (0.3) & w:1.5 (0.4), h:0.8 (0.2) & 1 \\
\hline N7 & $\begin{array}{l}-3.5 \mathrm{MPN} \\
12.8 \mathrm{TN} \text { posterior }\end{array}$ & $\begin{array}{l}14.5 \\
14.5\end{array}$ & $\begin{array}{l}\text { w:1.8 (0.5), h:1.5 (0.3) } \\
\text { w:2.0 (0.8), h:1.5 (0.5) }\end{array}$ & $\begin{array}{l}\text { w:1.3 (0.2), h:1.0 (0.1) } \\
\text { w:1.9 (0.3), h:1.5 (0.2) }\end{array}$ & 2 \\
\hline N8 & $\begin{array}{l}\mathrm{TN} \text { surface } \\
2.0 \mathrm{TN} \text { anterior }\end{array}$ & $\begin{array}{l}84.0 \\
44.0\end{array}$ & $\begin{array}{l}\text { w:0.6 (0.1), h:0.3 (1.4) } \\
\text { w:1.1 (1.7), h:0.8 (1.0) }\end{array}$ & $\begin{array}{l}\text { w:0.8 (0.3), h:0.4 (0.4) } \\
\text { w:0.7 (0.1), h:0.5 (0.2) }\end{array}$ & 2 \\
\hline N9 & $\begin{array}{l}\text { Separately descending } \\
10.0 \mathrm{TN} \text { posterior }\end{array}$ & $\begin{array}{l}\text { Proximal to } 89.0 \\
22.0\end{array}$ & $\begin{array}{l}\text { w:0.7 (0.6), h:0.5 (0.4) } \\
\text { w:1.8 (0.4), h:1.2 (0.2) }\end{array}$ & $\begin{array}{l}\text { w:0.5 (0.9), h:0.3 (0.7) } \\
\text { w:1.1 (0.3), h:1.0 (0.2) }\end{array}$ & 2 \\
\hline N10 & $75.5 \mathrm{TN}$ posterior & 83.0 & w:1.2 (0.2), h:0.8 (0.3) & w:1.0 (0.2), h:0.6 (0.2) & 1 \\
\hline N11 & $-4.9 \mathrm{TN}$ posterior & 14.0 & w:0.4 (0.3), h:0.3 (0.6) & w:0.3 (0.3), h:0.2 (0.2) & 1 \\
\hline N12 & $\begin{array}{l}-3 \mathrm{TN} \text { anterior } \\
-12 \mathrm{TN} \text { posterior }\end{array}$ & $\begin{array}{l}7.0 \\
\text { distal to MMC }\end{array}$ & w:1.5 (1.4), h:1.1 (0.6) & $\begin{array}{l}\text { w:1.9 (0.7), h:0.7 (0.6) } \\
-\end{array}$ & 2 \\
\hline N13 & $\begin{array}{l}\text { Separately descending } \\
10.0 \mathrm{TN} \text { anterior }\end{array}$ & $\begin{array}{l}\text { Proximal to } 96.0 \\
18.0\end{array}$ & $\begin{array}{l}\text { w:1.2 (0.2), h:0.6 (0.2) } \\
\text { w:0.7 (0.4), h:0.5 (0.3) }\end{array}$ & $\begin{array}{l}\text { w:0.8 (0.8), h:0.8 (0.4) } \\
\text { w:0.7 (0.7), h:0.5 (0.5) }\end{array}$ & 2 \\
\hline
\end{tabular}

Position is taken in the proximal direction, relative to the MMCA

from the TN in up to $0-44 \mathrm{~mm}$ from the MMCA. On average the separable length was $17.5 \mathrm{~mm}$. In one case (N4 in Table 5) the merge point was found from the photographs to be distal to the branching point measured externally. The reason for this is the shrinkage and loss of nerve tissue due to the processing of the nerve performed before the photographs were taken, as further described in the discussion. Only one branch showed no separability.

In terms of specimens (choosing the most separable CBs in cases of multiple CBs) the maximal separability of a $\mathrm{CB}$ was in the range of 7-23.6 mm, excluding the five specimens with separately descending CBs and the one with a merge point more proximal than $68 \mathrm{~mm}$ from the MMCA (N3, in Table 5). In average this gave a separable length of $14.8 \mathrm{~mm}$. This means that in six $(60 \%)$ of the specimens the separability length was longer than $68 \mathrm{~mm}$, and for the remaining four (40\%), the maximum separability length was on average $14.8 \mathrm{~mm}$, and no specimens showed no separability of any CB.

\section{Cross-sectional size of the TN}

At the MMCA, the width of the cross-sectional area of the $\mathrm{TN}$ varied within $4.2(0.6)-9.7(0.3) \mathrm{mm}$ (the number in the parentheses gives the additional size of the connective tissue) and the height varied within $2.0(0.3)-3.7$ (1.3) $\mathrm{mm}$. The averages and standard deviations given as: averages/ standard deviation were for the width: $6.8 / 1.7(0.7 / 0.6) \mathrm{mm}$ and for the height: $2.8 / 0.7(0.9 / 0.7) \mathrm{mm}$.
At the merge point of the MPN and LPN, the width varied within $4.2(0.3)-6.6(0.7) \mathrm{mm}$ and the height within $2.2(0.7)-3.8(0.7) \mathrm{mm}$. The averages and standard deviations given as: averages/standard deviation were for the width: 5/0.7 (0.6/0.3) $\mathrm{mm}$, and for the height: 2.9/0.5 (0.7/ $0.3) \mathrm{mm}$ (Table 4).

The thickness of the connective tissue varied between 0.2 and $2.5 \mathrm{~mm}$, but was usually $<1 \mathrm{~mm}$, and was often unevenly distributed around the nerve.

\section{Cross-sectional size of the MPN fascicle group}

At the MMCA, the width of the MPN fascicle group varied within $2.5(1.0)-5.7(0.4) \mathrm{mm}$, and the height varied within $1.2(0.7)-2.7(1.1) \mathrm{mm}$. The average/standard deviations of the width were $3.6 / 1.0(0.7 / 0.5) \mathrm{mm}$ and of the height: $2.1 /$ $0.5(0.6 / 0.3) \mathrm{mm}$. At the merge point, the width varied within 2.6 (1.3)-4.5 (0.7) $\mathrm{mm}$, and the height varied within 1.5(0.7)-2.6 (0.4). The average/standard deviations of the width were 3.4/0.6 (0.7/0.4) $\mathrm{mm}$ and of the height: $2.2 / 0.4$ $(0.7 / 0.5) \mathrm{mm}$ (Table 4).

\section{Cross-sectional size of the LPN fascicle group}

At the MMCA, the width of the LPN fascicle group varied within $2.4(0.3)-5.7(0.9) \mathrm{mm}$, and the height within 1.8 (1.6) $-2.5(0.8) \mathrm{mm}$. The average/standard deviations of the width were 3.1/1.1 (0.7/0.4) and of the height: 2.2/0.2 (0.7/ $0.7) \mathrm{mm}$. At the merge point, the width varied within 2.0 
(0.6)-3.9 (0.7) $\mathrm{mm}$ and the height within 1.3 (2.5)-2.6 (0.3) $\mathrm{mm}$. The average/standard deviations of the width were $2.7 / 0.6(0.6 / 0.3) \mathrm{mm}$ and of the width: 2.0/0.4 (0.7/ 0.7) $\mathrm{mm}$ (Table 4).

\section{Cross-sectional size of calcaneal fascicle group}

At the MMCA, the width of the CBs varied within 0.4 $(0.3)-2.0(0.8) \mathrm{mm}$ and the height within $0.3(0.6)-1.5$ $(0.5) \mathrm{mm}$. The average/standard deviations of the width were 1.3/0.5 (0.7/0.7) and of the height: 0.9/0.4 (0.6/0.5).

At the merge point (proximal end of the specimen for the separately descending $\mathrm{CBs}$ ), the width varied within 0.3 (0.3)-1.9 (0.7) $\mathrm{mm}$ and the height within $0.2(0.2)-1.5$ $(0.2) \mathrm{mm}$. The average/standard deviations of the width were $1.0 / 0.5(0.5 / 0.3)$ and of the height: $0.7 / 0.3(0.5 /$ $0.5) \mathrm{mm}($ Table 5).

\section{Discussion}

For the majority of the specimens, the bifurcation of the TN into the LPN and MPN was located in the tarsal tunnel (eight specimens, $80 \%$ ), which agrees well with Davis and Schon (1995). In one case, the TN bifurcated distally to the tarsal tunnel, which has not been reported in the previous studies (Table 1).

The TN gave off more than one CB in five (50\%) of the cases. This is in contrast to older studies of the $\mathrm{CB}$ branching patterns, but agrees well with the more recent study of Davis and Schon (1995).

Proximal to the MMCA, the LPN and MPN fascicle groups were separable for an average length of $18.7 \mathrm{~mm}$. The maximum separability length was $41 \mathrm{~mm}$, and in two cases the $\mathrm{TN}$ was not separable at all.

In six $(60 \%)$ of the cases, the specimen had a CB descending separately from the $\mathrm{TN}$ from a location more than $68-90 \mathrm{~mm}$ proximal to the MMCA. Excluding the separately descending CBs, the separability length for the remaining four $(40 \%)$ cases was $7-23.6 \mathrm{~mm}$.

The dimensions of the nervous tissue are expected to change during the processing of the nerves. At least two factors may be involved. Firstly, the nerves shrink during fixation, dehydration and embedding. Secondly, cutting the nerves into 3-mm-wide segments followed by sectioning in the microtome may cause additional loss of tissue, which should be taken into account when interpreting the numbers in Tables 2, 3, 4 and 5. Tissue shrinkage related to the formalin fixation occurs within $14 \mathrm{~h}$ and is estimated to be in the order of $4 \%$, as suggested by a study on prostate cancer (Schned et al. 1996). Further, the axial shrinkage of the nerves due to dehydration was estimated by measuring the length of eight nerve specimens before and after dehydration. The average shrinkage was $5.3 \pm 1.4 \%$ (SD). The loss of nerve tissue due to the mechanical processing was evaluated in six specimens and estimated to be $5.9 \pm 3 \%$ (SD). In one nerve the contribution to this average from (1) cutting the nerve into $3-\mathrm{mm}$ pieces and (2) slicing the nerves with the microtome was found to be $50 \%$. The total loss/shrinkage of the nerves was calculated to be $11.8 \pm 4.8 \%$ ( $\mathrm{SD} n=6)$ in the axial direction with an estimated additional $4 \%$ due to the fixation in formalin. Thus, the total axial shrinkage is estimated to $15.8 \%$. Assuming that the cross-sectional loss is similar to the measured axial loss due to dehydration and fixation, a total cross-sectional shrinkage of $9.3 \%$ is estimated. Additional shrinkage due to the staining procedure might have taken place. Still, the cross-sectional shrinkage may be smaller than this since the expansion of the 4- $\mu$ m-thick slices in the water bath, after slicing the nerve with the microtome, causes swelling and expansion of the tissue. Therefore, in the case of prostate cancer, a microscope-ready slide showed only a $4.3 \%$ shrinkage in total after fixation in formalin and embedding in paraffin (Schned et al. 1996).

The study of the fascicular patterns of the LPN, MPN and CB fascicular groups showed no interfascicular communication among the groups distal to the merge points of the nerves, but within the groups there was clearly a merging and splitting of the fascicles. This is in accordance with the results of Terzis and Smith (1990), opposing the descriptions by Sunderland (1978), who suggest exceeding inter fascicular communication. In the majority of the cases, the fascicles belonging to a certain group tended to stay at the same side of the nerve throughout the length of the specimen.

This length in which the TN was separable into the LPN and MPN is in the lower range of what is desirable for implantation of nerve cuff electrodes, since the cuff should preferably not be implanted in a place where there is too much motion of the surrounding tissue, as is the case near the MMCA during ankle extension and flexion. Further, the $\mathrm{S} / \mathrm{N}$ ratio of the recorded nerve signal increases with cuff length. Therefore, the cuff should have a length in the range of at least $15-30 \mathrm{~mm}$, depending of the diameter of the nerve fibres (Andreasen and Struijk 2002, 2003b; Stein et al. 1975). The fact that half of the specimens had CBs that were separable for more than $70 \mathrm{~mm}$ gives a good possibility of implanting a cuff with two channels, one for the $\mathrm{CB}$ and one for the TN. The fascicular pattern with the fascicles tending to descend with a consistent cross-sectional position within the TN suggests that a cuff with multiple electrodes (Struijk et al. 1996) may be used for selective recording from the $\mathrm{TN}$, even proximal to the merge points.

In general there was a high variability in the separability of the TN, also at the fascicular level, which agrees with 
the finding of significant fascicular branching patterns of peripheral nerves by Kudoh and Sakai (2007).

Therefore, a MRI scanner (Farooki et al. 2001) may be useful to obtain knowledge about the TN branch patterns for a particular case prior to a cuff implantation.

Acknowledgments We thank Mette Bille for her great assistance with embedding and slicing the nerves, and Jens Søndergaard Petersen, MD, for skilful assistance with the dissections. Further, we thank the European Commission, for funding this work through the BIOMED-2 program BMH-CT96-0897.

\section{References}

Andreasen LNS, Struijk JJS (2002) Signal strength versus cuff length in nerve cuff electrode recordings. IEEE Trans Biomed Eng 49:1045-1050

Andreasen LNS, Struijk JJS (2003a) Skin contact forces extracted from human nerve signals - a possible feedback signal for FES aided control of standing. IEEE Trans Biomed Eng 50:13201325

Andreasen LNS, Struijk JJS (2003b) Artefact reduction with alternative cuff configurations. IEEE Trans Biomed Eng 50:1160-1166

Andreasen LNS, Struijk JJ (2006) Model-based evaluation of the short circuited tripolar cuff configuration. Med Biol Eng Comp 44:404-413

Andreasen LNS, Struijk JJ, Lawrence S (2000) Measurement of the performance of nerve cuff electrodes for recording. Med Biol Eng Comp 38:447-453

Bareither DJ, Genau JM, Massaro JC (1990) Variation in the division of the tibial nerve: application to nerve blocks. J Foot Surg 29:581-583

Davis TJ, Schon LC (1995) Branches of the tibial nerve: anatomic variations. Foot Ankle 16:21-29

Dellon AL, MacKinnon SE (1984) Tibial nerve branching in the tarsal tunnel. Arch Neurol 41:645-646

Farooki S, Theodorou DJ, Sokoloff RM, Theodorou SJ, Trudell DJ, Resnick D (2001) MRI of the medial and plantar nerves. J Comput Assist Tomogr 25:412-416

Gray H (1995) Anatomy, 38th edn. Churchill Livingstone, New York

Haugland MK, Sinkjær T (1995) Cutaneous whole nerve recordings used for correction of footdrop in hemiplegic man. IEEE Trans Rehabil Eng 3:307-317
Haugland MK, Lickel A, Riso RR, Adamczyk MM, Keith M, Jensen LI, Haase J, Sinkjær T (1997) Restoration of lateral hand grasp using natural sensors. Artif Organs 21:250-253

Havel PE, Ebraheim NA, Clark SE, Jackson WT, DiDio L (1988) Tibial nerve branching in the tarsal tunnel. Foot Ankle 9:117119

Hoffer JA (1990) Techniques to study spinal-cord, peripheral nerve and muscle activity in freely moving animals. Neurophysiological techniques: applications to neural systems. Neuromethods 15:65-145

Horwich MT (1938) Normal anatomy and variations of the peripheral nerves of the leg and foot. Arch Surg 36:626-636

Kudoh H, Sakai T (2007) Fascicular analysis at perineurial level of the branching pattern of the human common peroneal nerve. Anat Sci Int 82:218-226

Nagoaka M (1990) An anatomical study of tarsal tunnel. Nippon Seikeigeka Gakkai Zasshi 64:208-216

Navarro X, Krueger TB, Lago N, Micera S, Stieglitz T, Dario P (2005) A critical review of interfaces with the peripheral nervous system for the control of neuroprostheses and hybrid bionic systems. J Peripher Nerv Syst 10:229-258

Rondhuis JJ, Huson A (1986) The 1st branch of the lateral plantar nerve and heel pain. Acta Morphol Neerl Scand 24(4):269-280

Sammarco GJ, Conti SF (1994) Anomalous tibial nerve. A case report. Clin Orthop 305:239-241

Sarrafian SK (1983) Anatomy of the foot and ankle, descriptive, topographic, functional. J.B. Lippincott, Philadelphia

Schned AR, Wheeler KJ, Hodorowski CA, Heaney JA, Ernstoff MS, Amdur RJ, Harris RD (1996) Tissue-shrinkage correction factor in the calculation of prostate cancer volume. Am J Surg Pathol 20:1501-1506

Stein RB, Charles D, Davis L, Jahamandas J, Mannard A, Nichols TR (1975) Principles underlying new methods for chronic neural recording. Can J Neurol Sci 2:235-244

Struijk JJ (1997) The extracellular potential of a myelinated nerve fiber in an unbounded medium and in nerve cuff models. Biophys J 72:2457-2469

Struijk JJ, Haugland MK, Thomsen M (1996) Fascicle selective recording with a nerve cuff electrode. Proceedings of 18th annual international conference of the IEEE engineering in medicine and biology society, Amsterdam

Sunderland S (1978) Nerves and nerve injuries. E. \& S. Livingstone, Edinburgh

Terzis JK, Smith KL (1990) The peripheral nerve, structure, function, reconstruction. Hampton Press Publication, Raven Press, New York 